\section{THE PREPARATION OF GLYCERINATED} CALF LYMPH.

In the Milroy Lectures, Dr. Monckton Copeman gives full details of the mode of preparation of glycerinated calf lymph, the use of which it is proposed to make compulsory. The chief points are (1) the quarantining of the calf to ensure that it is healthy ; (2) the sterilisation of the seat of inoculation; (3) the inoculation of the incisions, which are about four inches long and half an inch apart; (4) after five days the collection of the vaccine pulp. This is done by sterilised instruments amid as completely aseptic conditions as can be obtained. It is in this stage that the chief difficulty arises, the only organisms met with which resist the germicidal action of glycerine being the hay bacillus and the $B$. mesentericus, and their intrusion is doubtless due to difficulties in the way of cleansing the vesicles. In collecting the pulp the whole of the vesicles and their contents are removed by a Volkmann's spoon. (5) The preparation of the lymph pulp. This is first weighed, and is then thoroughly triturated, and when it has been brought to a state of fine division it is mixed with six times its weight of a sterilised solution of 50 per cent. pure glycerine in distilled water. The emulsion so produced is stored in test tubes in a cool, dark place, and when required is drawn up into sterilised capillary tubes, which are sealed as usual. (6) Bacteriological examination of the emulsion is made at regular intervals, and usually at the end of four weeks all extraneous organisms are found to have died out. (7) Meanwhile, after the collection of the pulp the calf is transferred to the slaughter-house and examined by the veterinary surgeon, who forwards a certificate of its condition. Should this not prove satisfactory the pulp is all destroyed. Looking at the matter from a scientific standpoint, no one can doubt the immense advance which this process shows in every point over the happy-go-lucky methods of vaccination which have been far to common in this country. We cannot bat feel, however, that the manufacture of a product of this kind should be carried out under the strictest guarantees, such as can only be satisfactorily given by a Governmentinstitution; for there can be but little doubt that much of the prejudice which many medical men have felt against calf lymph has been due to the varying results which have been said to follow the use of samples derived from different sources.

THE TEACHING OF ELEMENTARY SCIENCE.

The resolution of the Royal College of Physicians in regard to the teaching of elementary scientific subjects is likely to land the medical schools in a very considerable difficulty. According to the proposed arrangement the first of the five years required to be devoted to professional study may be spent in obtaining instruction in chemistry, physics, practical chemistry, and biology, either at a recognised institution (i.e., a place other than a medical school) or at a recognised medical school, leaving only four years which must elapse between joining the medical school and entering for the final examination; and it is only to be expected that a very large proportion of the students of the future will elect to get rid of these subjects before going up to the bospitals. Under these circumstances, the medical schools will have to ccnsider whether it will be worth their while to keep up their laboratories and all the expensive machinery which is required for the teaching of these subjects to the small residuum of students who will enter for the first year. Much will depend upon the number of "institutions" which are "recognised" as places of study. But if technical schools and highergrade Board Schools are to be recognised, as has been suggested, it is clear that the economy of getting through their chemistry, physics, practical chemistry, and biology before joining will be so great that but few will be left to repay the medical schools for their outlay on the teaching of these subjects. A great opportunity, then, is likely to offer itself to the medical schools of London to get rid of a quantity of useless top-hamper in the way of physics, biology, and chemistry teaching, if they will but combine so to do. Unfortunately, the trustful parent has to be impressed by the prospectus, and it is to be feared that schools will hesitate to admit that they are not complete. With the steady growth and importance, however, of bacteriology and of physiological and pathological chemistry, the space at the disposal of the schools might well be devoted to these higher branches, and some form of combination school might be formed, at which the elementary science subjects might be taught to such students as had not been connected with "recognised institutions." Something of this sort would clear the board immensely, and would be one step towards leaving the medical schools none but medical matters to deal with.

\section{THE OPEN-AIR TREATMENT OF PHTHISIS.}

It does not speak well for the healthiness of our dwelling-houses that the mere placing of a patient in the open air should relieve him of much of his distress and remove many of his most important symptoms. Such, however, seems to be the case in regard to phthisis.

The open-air treatment of pulmonary tuberculosis is a matter which is forcing itself strongly upon professional attention at the present time, for its efficiency is well vouched for by many well-known physicians.

The last pronouncement in its favour comes from Dr. Theodore Williams, who has for a long time back adrocated the treatment of phthisis by residence at high altitudes. He, however, in no way modifies his views as to the utility of high altitudes. There is in them, no doubt, something specific, connected probably with the development of compensatory changes in the healthy lung, connected possibly with those changes in the condition of the blood which are induced by mountain air. Nevertheless, the régime adopted by those undergoing the Alpine cure is to a large extent the same as in that by open air; and although it may be admitted that high altitudes are the more efficacious, it is clear that the life in the open air, which is the active agent in the "cures" at a lower elevation, alss play no mean part in the striking results obtained at Davos, in the Andes, and elsewhere.

The position to which we have now reached seems to. be this, that true as it is that in the glorious sunshine in the Alps the open air is more agreeable, and that in the keen dryness of those favoured health resorts the stimulating effects of the mountain air make it easier for a due amount of exercise to be taken, yet that, so far as living in the open is concerned, it is 